\title{
A Stylistic Analysis of Some Linguistic Devices in Newspaper Headlines: Nigerian Newspapers as a Case Study
}

\section{Folorunso Oloruntobi}

Department of English and Literary Studies, Faculty of Arts, University of Abuja, Abuja, Nigeria.

\begin{tabular}{|c|c|c|c|}
\hline Received: 01.11.2020 & - Accepted: 05.12.2020 & Published: 31.12 .2020 & Final Version: 31.12 .2020 \\
\hline
\end{tabular}

\begin{abstract}
Media houses have played significant roles in national development. They, among other roles, serve as the intermediary between the government and the masses. The choice they make in their reportage begins from the headlines which may or may not outrightly show the direction of the news. The study examines the linguistic features of the news headlines on fuel subsidy removal and electricity tariff hike in Nigeria. Register analysis is the theory adopted to carry out the study. This is to enable us consider the functions of the chosen linguistic items within the social setting; find out the similarities and differences that exist among the headlines in terms of how they are structured and point out the implied meaning in them. This study, among other findings, reveals that most of the newspaper headlines on fuel subsidy removal and electricity tariff hike relied heavily on positive adjectives to palatably present government policies, actions and steps to the masses. This paper suggests that researchers could adopt Speech Act Theory to analyse the newspaper headlines on fuel subsidy removal and electricity tariff hike so as to find out what journalists are doing with words.
\end{abstract}

Keywords: Electricity tariff, Subsidy, Stylistic Analysis, Newspaper Headlines, Systemic Functional Linguistics

\section{Introduction}

The Federal Government of Nigeria recently increased fuel price and simultaneously, astronomically pushed up the cost of electricity. This has taken a heavy economic toll on the masses. These increases came amidst the economic woes that befell the nation, arising from the nagging pandemic (Covid19). The print media which are strong instruments of shaping the opinions of the masses and generating civil discourse on national issues came all out and reported the issue.

Van Dijk (2008) holds the opinion that the print media play the role similar to that of a prism, either presenting reality undiluted or distorting reality. The media outfits have the right and obligation to present the news objectively. Taking into consideration the times we are when mass gatherings are discouraged by the government, the media outfits also owe the responsibility to ensure that they avoid incendiary reports to counteract the protests which could lead to national health disaster. National interest is paramount.

On September 8, 2020, virtually all newspapers captured the news on fuel subsidy removal and electricity hike in their reports. The news made it to the front pages which always attract readers. This gave the issue the prominence it deserved.

This study attempts to analyze newspaper headlines on fuel subsidy removal and electricity tariff hike as reported by nine print media which are randomly selected. These are Daily Trust, The Punch, 

Case Study

Daily Sun, Nigerian Pilot, Blueprint, The Nation, Nigerian Tribune, Daily Independence and New Telegraph.

\section{Literature Review}

Ifantidou (2009) said the single function of newspaper headlines is "attention-getting rather than information-providing device since headlines do not accurately represent the articles they introduce. In other words, newspaper headlines are persuasive rather than informative'. Olugbenga (2020) posits that headlines play important roles in orienting the readers' attention and interpretation of the facts contained in the story or article. While it may be true in some instances that editors capture the attention of their readers through their headlines, journalists do not merely use their newspapers headlines to get attention only. Headlines are more or less similar to the torchlight of writers. They are used to call the attention of readers to an issue in a particular way, making them view an issue from a particular perspective.

Stainton (2004) claims that "much of news headlines may be considered as nonsentences", while Freeborn et al. (1986) conclude that "technology of printing includes choices in terms of style, availability of space and accompanying photographs. Other criteria include simplicity, informality and impact". Reah (1998) reveals that a headline is an autonomous text which carries various functions within the newspaper's discourse and has specific features as regards language use.

Develotte and Rechniewski (2001) submit that the headlines are more crucial for the readers than news articles themselves because they are capable of revealing social, cultural or national representations. BBC (2003) describes the headline of a story as 'the short summary, which appears above stories or articles in a newspaper'.

Agu (2010) explains that it is common to discover that the headlines of news stories or articles are written with either nominal or verbal ellipses. Ellipsis is one of the grammatical processes that editors exploit to avoid needless repetition, list comments made by one speaker, economise space, create ambiguity and 'quietly say' some things, leaving the readers with an option of inference.

Olugbenga (2020) stresses that journalists have special methods of using words in captioning headlines so as to capture the interest of the readers, or to exhibit the editorial policy of the media outfit they represent. Newspaper reporters tactfully use words either to uphold the policy direction of their employers or to skillfully use lexical items to project an ideology, to promote an idea, and either explicitly or implicitly to convince the unsuspecting masses to accept their garnished thought.

In his opinion, Olugbenga, (2020) states that the press has the responsibilities of determining and accessing a news item; the appropriate time, form and where it will be published to suit the prevailing social circumstances.

Jonah (2012) posits that newspaper editorials, to a large extent, share common characteristics, but differ in style and form as it has been established in 'The Nation' and 'This Day' newspapers. All the news items are given titles (headlines) so as to point the central focus of the news but sometimes the headlines do not indicate the direction of the news but create curiosity in the readers. They also adopt ungrammatic convention in structuring their sentences such as the use of full colon and sometimes, their headlines, even the ones in full sentences, deliberately fail to attract a full stop.

Williams (2003) opines that newspapers are particularly known to initiate discourse on key national issues by quoting statements and 'dramatizing' actions of prominent national figures, celebrities and happenings around the nation and exposing them to their readership. Abba and Musa (2015) assert that the role headlines play as pointers to the news makes them to be captioned in a way that they 
are in most cases manipulated in terms of linguistic features so as to, some degree, influence the readership. The editor stylistically makes the choice of which report is more important to his readers.

Bell (1991) argues that "most editors ensure that the choice of expressions in headlines usually reflects the feelings, opinions and attitudes of people about issues in the news". In most cases, editors or reporters strive to make their linguistic choices reflect the feelings, opinions, attitudes and reactions of people about issues in the news and that starts from the headlines which can be liken to "heart" of the news. One other thing that determines the linguistic choice of an editor is the sociosecurity atmosphere as an editor's lexical choice can either heighten or dampen the existing tension in the nation.

Agu (2010) stresses that journalists may choose to make or mar the nation which has been built over the year through the use of words. Newspaper editors through their headlines play a crucial role in shaping issues in the society and setting the boundaries of what is talked about and how it is talked about (Henry and Tator, 2002).

This study contributes to the studies on the language of media as it goes a step further than the previous studies to, not only analyse the linguistic items in the newspaper headlines but also compare the linguistic choices made in framing each headline so as to establish the similarities and differences that exist among them, and find out the linguistic essence of such sameness and otherwise.

\section{Methodology}

In this study, nine newspapers were randomly selected for study for two reasons: one being that as topical as the issue was, some newspapers did not deem it fit to report it, so there were no headlines concerning the news in some newspapers. Another reason was that some headlines were so similar that taking both of them might lead to fruitless repetition. All the headlines in each of the chosen newspapers relating to the hike and the removal, except the ones that are lexically similar to each other, were taken for analyses. This enabled us to view the facts in each newspaper in their raw state, just as the editor presented them.

Overall, forty-eight headlines appeared on the nine selected newspapers concerning the matter, twenty-two of which were chosen for analysis. In addition, the linguistic features which accounted for the similarities and differences in the headlines were analysed while the reasons for such sameness and dissimilarity in the choice of available linguistic options were highlighted.

\subsection{Theoretical Framework}

Systemic Functional Linguistics (SFL Hencefoth) was largely developed by Halliday and his followers during the 1960s in the United Kingdom. SFL is built on previous works of some influential linguists such as Bronislaw Malinowski and J.R Firth (O'Donnel, 2012). This theory holds that a language is a bundle of systems, and that at every level of language, there are options available to a language user. The social function a language performs determines its structure. Because of the concern of SFL with the use of language, great importance is placed on the function of language (Matthiessen and Halliday, 1997).

SFL is a broad theory with many aspects. One of the aspects of the theory is register analysis. Halliday (1985) describes register as a 'variety of language, corresponding to a variety of situation'. He stresses that the term register is more properly theorized as continuous variation along many linguistic dimensions. Martin and colleagues in Moore (2017) see register as a setting in field, tenor or mode. 

Case Study

Ulfah (2010) highlights the characteristics of register study as follows. It involves descriptive analysis of actually occurring discourse and aims to characterize language varieties. Also, register study presents formal linguistic characterizations of language varieties and analyses the situational characteristics of language varieties, and functional or conventional relationships between form and situation.

Modality as another aspect of SFL is analysed in terms of its interactional and pragmatic functions to take up different stances towards the hearer and the message (Aijmer, 2015). This analysis is imperative in that the grammar of a language constitutes a system which needs to be described and match with its function within the context of discourse (Butler, 2003). Hunston (2011) argues that we also need to recognize modal-like expressions appearing in contexts that signal modal meanings though the modal meaning is realized in ways that are not usually considered modal. Nuyts (2001) distinguishes four different expression types which are found in Western European languages: modal adverbs, modal adjectives, mental state predicates, modal auxiliaries. Perkins (1983) recognizes a class of modal expressions which transcend the limit of modal auxiliaries and includes semiauxiliaries, adjectival, participial and nominal modal expressions, modal adverbs and lexical verbs. Aijmer (2015) posits that functional approaches to modality generate new issues, perspectives, and views.

In addition, transitivity is a system of the clause, affecting not only the verb serving as a process but also participants and circumstances. According to Halliday (1994), 'reality is made up of processes of going on, happening, doing, sensing, meaning, being and becoming'. Matheson (2005) states that transitivity focuses on each clause in the text, 'asking who are the actors, who are the acted upon, and what processes are involved in that action'. Halliday in Ezzina (2015) mentions three components that each situation type is made up of: 'the process itself, participants in the process, and the circumstances associated with the process'. The process is realized by a verb and it is the core part of the situation. Participants are realized by a nominal group and circumstances are realized by adverbial groups or prepositional phrases.

This study adopts register analysis because of its focus on registers and structures, analysing and classifying them within the context of discourse. It analyses the situational characteristics of language varieties, and presents the functional relationship that exist between form and situation.

\section{Findings and Discussion}

\subsection{Lexical Features}

This study shall examine how the choice of words, coordination patterns and structural options may help in the understanding of the headlines on fuel subsidy removal and electricity tariff jack, and the perspective from which each media outfit contributes to national development. It would also enable us to conclude whether there is resemblance or disparity in their positions in relation to subsidy removal and tariff uprise.

\subsection{Adjectives}

The following words are used in the headlines on fuel subsidy removal and electricity tariff increase: irreversible, necessary, cheapest, anti-masses, dangerous, negative, provocative, toothless, Labour's, abysmal, economic, irresponsible, mischievous, unnecessary, lowest, tariff's, sustainable, feasible, cheapest. 
Let us consider how they were used in sentences:

1) Fuel subsidy removal irreversible, electricity tariff hike necessary (Daily Trust)

2) Buhari says subsidy dangerous (The Punch)

3) Justification of hike provocative (Daily Sun)

4) Borrowing to subsidize electricity grossly irresponsible (Nigerian Pilot)

5) Reactions to \#162/litre mischievous, unnecessary (Blueprint)

6) Tariffs in Nigeria among lowest in W/A (The Nation)

7) Says \#1.7trn on electricity subsidy no longer sustainable (Nigerian Tribune)

8) Says petrol, electricity subsidies no longer feasible (Daily Independent)

From the data above, it is obvious that various editors used more effective adjectives as useful linguistic devices to sell the decision of the government to the masses. Doing this, they recurrently used predicative adjectives, which in this case are negative adjectives, to condemn any reactions from the opposition (mischievous, unnecessary) because they chose to make the man on the street believe that what was obtainable in the past can, in the face of the unfortunate economic challenges, no longer be achieved (sustainable, feasible).

In addition, a critical study of the adjectives revealed that provocative which is a negative adjective was considered in one of the headlines to condemn any attempt by the government to give reasons for their policies and justification attempt could be counterproductive. This could be an implicit warning to the government to, as soon as possible, reverse the decisions.

Though the opposition may be provoked by the increases, the decisions of the government are irreversible and should be regarded as the necessary economic measures to take the country out of the current economic quagmire. They attempt to convince Nigerians that the status quo of subsidy regime is not only irresponsible but also economically dangerous. In an attempt to douse any tension or agitation, The Nation used a gradable adjective (lowest) at superlative level, comparing tariff in Nigeria to other West African countries. This seems to suggest to Nigerians that they can still survive under the current economic realities.

The analysis above reveals that most of the selected headlines on fuel subsidy removal and electricity tariff jack are deliberately framed to promote government policies; so, they effectively chose words that would convince the masses and justify the decision of government. It could be that the editors hold the view that building infrastructures would contribute more to national development than subsidizing fuel and electricity tariff.

\subsection{Nouns}

The nouns that are used in the headlines are as follows:

fuel, subsidy, electricity, power, tariff, price, petrol, government, Nigeria, Nigerians, labour, effect, hike, protest, provocation, anger.

The nouns above are registers of economy and they are simple enough for an average Nigerians to understand without referring to a dictionary since they are household words. The choice of simple and accessible words could be to ensure that every interested reader understands the headlines as easily as possible. The words unambiguously reveal that the selected headlines refer to the country, Nigeria. The aspects of the Nigerian economy that are concerned are also clearly stated. The parts of the economy are electricity (also called power) and fuel. These aspects of the economy have direct 

Case Study

effect on the people of the country called Nigerians. The choice of nominal elements in the chosen headlines depicts that three categories of people are involved: government (the policy makers), Labor (the mediator between the government and the masses), Nigerians (the masses).

The policy of government that informed the headlines revolves around price of commodities which in the context of electricity is called tariff. This suggests that all customers (Nigerians) would spend more of their income on these two indispensable commodities because government has decided to remove fuel subsidy which invariably means that the unit price of petrol automatically goes up and electricity tariff has also been raised by the government. So, these result in hike in the cost for fuel and electricity. Thus, Nigerians' negative emotional reactions are appropriately captured in the following words: anger and provocation. The unwanted emotional reactions from the poor could possibly lead to detrimental physical reactions, protest.

The choice of the itemized registers in the favored headlines puts no one in doubt on the context in which the headlines on fuel subsidy removal and electricity tariff hike are based.

\subsection{Syntactic Features}

\subsubsection{Coordination}

A structural class that also contributes to the understanding of the headlines on fuel subsidy removal and electricity tariff increase is conjunction. The conjunctions preponderantly selected for the headlines are coordinating conjunctions while subordinators were scarcely employed. Their manifestations could be seen in the following headlines:

1. Fuel subsidy removal irreversible, electricity tariff hike necessary (Daily Trust)

2. Fuel queues will return if we continue subsidy (The Punch)

3. No going back on fuel subsidy removal, electricity (Daily Sun)

4. Fuel price hike, new electricity tariff have come to stay (Blueprint)

5. No return to petrol, power subsidy (The Nation)

6. We can't borrow to subsidize fuel, electricity (New Telegraph)

In headlines $1,3,4,5,6$, coordinating conjunctions were considered over subordinating conjunctions because structures of equal status were added together. Hence, the coordinating conjunction 'and' was employed, though covertly used to imply addition.

In addition, choosing between syndetic (overt) and asyndetic (covert) coordination, all the newspaper reporters wholly preferred asyndetic coordination, using comma in place of coordinator (and) without using even one overt coordinator. Asyndetic coordination is a linguistic tool to knot the two policies of government together.

In headline 2, however, The Punch used a subordinating conjunction to introduce an adverbial clause of condition for the return of fuel queues. This is a subtle way to sternly warn Nigerians not to force the government to reverse its decision as that would bring more hardship than what they would suffer, removing fuel subsidy.

\subsubsection{Clause}

Non-finite clauses such as clauses with to-infinitive verbs, ed/en participle verbs and ing-participle verbs are also the most preferable structural patterns for newspaper headlines on fuel subsidy removal and electricity tariff hike:

1. No going back on fuel subsidy removal, electricity (Daily Sun) 
2. We can't borrow to subsidize fuel, electricity (New Telegraph)

3. Govt promises to cushion effect (Daily Sun)

4. Borrowing to subsidize electricity grossly irresponsible (Nigerian Pilot)

5. Nigerians condemn Labour's failure to protest over hike in fuel price - (Nigerian Pilot)

6. Justifying petrol price hike act of provocation (Nigerian Tribune)

The choice of non-finite beta clauses in headlines as in 1 to 6 above has some stylistic effects. For instance, to subsidize fuel, electricity in headline 2 is adverbial, stating the purpose for which the government is not willing to take a loan. To cushion the effect (to-infinitive non-finite clause) in headline 3 is complement (extensive) which suggests the palliative that the government would give to the masses which would make them not feel the economic impact of the hikes. Borrowing to subsidize electricity (ing non-finite clause) in headline 4 is placed in subject position to enable the writer demean such action, using negative adjective at complement. Similarly, no going back in headline 1 is a nominal clause but which occurs in complement position as its subject (there) and verb (is) are removed to give prominence to an action that government does not want to take.

Also, to protest over hike in fuel price (to-infinitive non-finite clause in headline 5) is employed as a rankshifted clause (at qualifier) to describe the noun failure. The labour union has failed in its inability to perform its statutory function which is to protect the interest of the masses.

Non-finite beta clauses in headlines 1, 3, 4 and 6 are nominal while clause 5 is an adjectival clause. The nominal clauses are rankshifted to function as subjects (clauses 1 and 4) while clauses 1 and 3 function as complements, presenting the step that government would take to benefit the masses. The actions or steps that government wants to take or not to take are presented in progressiveness in headlines 1, 4, 6 but clause 5 which is adjectival qualifies the noun, failure.

\subsubsection{Sentence}

The highest grammatical structure, sentence, may also be significant in getting at the meaning of the headlines on fuel subsidy removal and electricity tariff hike. Though some of the sentences are elliptical, they could be fully realized and classified accordingly:

$\mathrm{S} \quad \mathrm{C} \quad \mathrm{A}$

1. Oil/ cheapest/ in Nigeria (Daily Trust)- minor/simple

$\mathrm{C}$

A

2. No going back/ on fuel subsidy removal, electricity tariff hike (Daily Sun)-minor/simple

$\mathrm{S} \quad \mathrm{P}$

C

3. Govt/ promises/ to cushion effect (Daily Sun)- Complex

$\mathrm{S}$

$\mathrm{C}$

4. Justification of hike/ provocative (Daily Sun)-minor/simple

$\mathrm{S}$

$\mathrm{C}$

5. Borrowing to subsidize electricity/grossly irresponsible (Nigerian Pilot) - minor/complex 
C

6.Toothless Labour- (Nigerian Pilot) - minor/simple

$\begin{array}{llll}\mathrm{S} & \mathrm{P} & \mathrm{C} & \mathrm{A}\end{array}$

7.You/'re pushing /Nigerians/ to the wall (Blueprint) - simple

$\mathrm{C}$

8.No return to petrol, power subsidy (The Nation)-minor/simple

S

$\mathrm{P}$

$\mathrm{C}$

9.Nigerians /condemn /Labour's failure to protest over hike in

fuel price - (Nigerian Pilot) - complex

$\mathrm{S}$

$\mathrm{C}$

10.Justifying petrol price hike/ act of provocation (Nigerian Tribune)-minor/complex

Main Clause

Main Clause

$\begin{array}{lllllll}\mathrm{S} & \mathrm{P} & \mathrm{C} & \mathrm{A} & \& & \mathrm{~S}\end{array}$

11.//Fuel subsidy/gulps/ \#10.41trn/ in 14 years// ,// electricity

$\mathrm{C}$

tariffs / \#1.7 trn// (Blueprint) -minor/ compound

$\mathrm{S}$

$\mathrm{C}$

12.Anger over fuel price/ mischievous (Daily Independent)-simple

The headlines above are a representation of all sentences, where we have simple sentences (both major and minor) and non-simple sentences (complex, compound, compound-complex sentences). It is clear that the choice of sentence types depends on what the editor wants to achieve.

In minor sentences where only verbs are ellipted such as in sentences $1,4,5,10$ and 12 , the reporters deliberately removed the main verbs since they do not portray any actions that are indispensably relevant to the meaning of the headlines but only joined the complements to the antecedents which such complements describe. Because the journalists are certain that their readers can easily supply such verbs where necessary, they dismiss the verbs.

On the other hand, in headlines 2, 6 and 8 both subjects and verbs are ellipted. The subject of items 2 and 8 is 'there' which is non-referent while the verb in both of them is 'is' which links the nonreferent pronoun (there) to complement where the meaning of the sentence lies. The subjects are thus ellipted, leaving only complement where the intended meaning lies. The ellipsis in sentence 6 is similar to that of headlines 2 and 8 because its subject and verb are removed but in this case, the choice of ellipsis or minor sentence could be a linguistic way of calling on the Nigerian Labour Congress to live to the expectation of the masses.

Examining the complexity of the headlines, out of the 12 headlines above, 7 of them are simple can be classified as simple sentences while only 5 are non-simple sentences. The preponderance use of 
simple sentences is as a result of the fact that many of the headlines made up of subjects and complements (in this case, adjectives usually) which either promote or condemn the nouns.

However, the choice of non-simple sentences in some of the headlines cannot be overlooked. For instance, headline 11 (compound sentence) could be to afford the writer the opportunity to present two similar facts to readers since the decision of the government to remove fuel subsidy and increase electricity tariff simultaneously is based on the facts.

\section{Findings}

The following are the findings of this study:

Firstly, predicative adjectives which are predominantly positive adjectives were preponderantly used across all the sampled headlines to beautify government policy of hikes in prices of fuel and electricity so as to convince the masses that the policies are in their interest. Also, there was the use of negative adjectives across all the chosen headlines to implicitly suggest that any action against the policies would not be in the interest of Nigeria.

Secondly, many of the non-finite beta clauses are nominal clauses which render some of the headlines under study non-simple sentences. This makes possible the compression of two issues into some of the headlines.

\section{Conclusion}

This study examined the language of the media, using the newspaper headlines with the aim of finding out the linguistic features employed in the headlines on fuel subsidy removal and electricity tariff hike in Nigeria, and establishing the linguistic features that are common to the selected headlines. The findings from this study reveal, in agreement with Develotte and Rechniewski (2001) and Olugbenga (2020), that the press plays a significant role in the stability of a nation by sieving what is published and determining the best way to put it to the masses to ensure the stability of a country.

Positive adjectives in the newspaper headlines were used to present the policies of government palatably to the common man. The choice of non-finite nominal clauses was basically a linguistic method of placing the steps and actions of either the government or the masses at subject position so as to describe them accordingly using appropriate adjectives as complement to qualify them.

\section{References}

\section{Primary Sources:}

[1] Daily Trust. Vol. 51, No. 22. Tuesday, September 8, 2020.print

[2] Daily Sun. Vol. 17, No. 4532. Tuesday, September 8, 2020.print

[3] The Punch. Vol. 44, No. 22,281. Tuesday, September 8, 2020. print

[4] Nigerian Pilot.Vol. 10, No. 213. Tuesday, September 8, 2020. print

[5] Blueprint. No. 2, 357. Tuesday, September 8, 2020. print

[6] The Nation. Vol. 13, No. 5152. Tuesday, September 8, 2020. print

[7] Nigerian Tribune.17,624. Tuesday, September 8, 2020. print

[8] Daily Independent. Vol. 18, No. 1657.Tuesday, September 8, 2020. print

[9] New Telegraph. Vol. 5, No. 2399. Tuesday, September 8, 2020. Print

Secondary Sources:

[10] Abba S. Tijjani, Olakunle A. Idris and Musa Nasir (2015). 'A Speech Act Analysis of 
56 Oloruntobi.: A Stylistic Analysis of Some Linguistic Devices in Newspaper Headlines: Nigerian Newspapers as a Case Study

Daily Trust Newspaper Headline Reports on Boko Haram Attacks". in Proceedings of The Academic Conference of African Scholar Publications \& Research International on Challenge and Prospects. Vol. 8 No. 3. 10th December, 2015 - Bauchi State University, Gadau, Bauchi State.

[11] Agu, I.E. (2010). " A Linguistic-Stylistic Analysis of Newspaper Reportage"' in Ospoly Journal of Language and Communication. Vol. 3(1), 164-182

[12] [12] Aijmer, Karin. (2015). "Modality and Mood in Functional Linguistic Approaches" in Oxford Handbooks Online. https://www.researchgate.net

[13] BBC (2003). News Report, Sports Commentaries Arts Review and More. London: BBC Worlds Service.

[14] Bell, A. (1991). The Language of the News Media. Oxford: Basil Blackwell.

[15] Butler, Christopher S. (2003). Structure and Function. A Guide to Three Major Structuralfunctional Theories. Part 1. Approaches to the Simplex Clause. Amsterdam and Philadelphia: John Benjamins

[16] Develotte, C. \& Rechniewski, E. (2001). "Discourse Analysis of Newspaper Headlines: A Methodological Framework for research into National Representations". Journal of French Media Studies.

[17] Ezzina, Rym (2015). "Transitivity Analysis of The Crying Lot of 49 by Thomas Pynchon" in International Journal of Humanities and Cultural Studies. Vol. 2 (3). Pp283- 287

[18] Freeborn, D. et al. (1986). Varieties of English: An Introduction to the Study of Language and Society. London: Macmillan.

[19] Halliday, M.A.K. (1985). An Introduction to Functional Grammar. London, Melbourne.

[20] Halliday, M.A.K.(1994). An Introduction to Functional Grammar. London: Edward Arnold.

[21] Henry, F. \& Tator, C. (2002). "Discourses of Domination: Racial Bias in the Canadian English-Language Press". Canadian Journal of Sociology. Toronto University Press.

[22] Hunston, Susan.(2011). Corpus Approaches to Evaluation. London and New York: Routledge.

[23] Ifantidou, E. (2009) "Newspaper Headlines and Relevance: Ad hoc Concepts in ad hoc Contexts”. Journal of Pragmatics, 41, 699-720

[24] Jonah, K. P. (2012): 'A Linguo-Stylistic Analysis of Newspaper Reportage on the 2010 and 2011 Crises in Jos: A Case Study of The Nation and This Day'. International Journal of Language, Literature and Gender Studies, Ethiopia. Vol. 1(1). 2012.

[25] Matheson, Donald. (2005). Media Discourses: Analysing Media Texts.

[26] Matthiessen, C. \& Halliday, M. (1997). Systemic Functional Grammar (1st ed.).

[27] Moore, Rotha Alison. (2017). "Register Analysis in Systemic Functional Linguistics".https//www.researchgate.net

[28] Nuyts, Jan.(2001). Epistemic Modality, Language and Conceptualisation: A Cognitivepragmatic Perspective. Amsterdam and Philadephia: John Benjamins.

[29] O'Donnell, M. (2012). Introduction to Systemic Functional Linguistics for Discourse Analysis. Language, Function and Cognition, pp 1-8.

[30] Olugbenga, S.A. (2020). "A Linguistics- Stylistic Analysis of Newspaper Headlines of Metele Attack on Nigerian Army by Boko Haram Insurgents'. International Journal of Scientific and Research Publications. Vol. 10, issue 2, 2020.

[31] Perkins, Michael R.(1983). Modal Expressions in English. London: Pinter

[32] Reah, D. (1998). The Language of Newspapers. London: Routledge.

[33] Stainton, R. (2004). "The Pragmatics of Non-Sentences". In The Handbook of Pragmatics. 266-287. Oxford: Blackwell.

[34] Ulfah, Yetty F.(2010). Register Analysis in English Movie Advertisement of www.21CINEPLEX.COM (A Sociolinguistics Study). Submitted as a Partial Fulfillment of Requirement for the Sarjana Degree in English Department, Sebelas Maret University, 
Surakarta.

[35] Van Dijk, T.A. (2008). Discourse and Context. A Sociocognitive Approach. Cambridge, UK: Cambridge University Press

[36] Williams, K. (2003). Understanding Media Theory. Great Britain. Arnold, Hodder Headline Group. 